\title{
$\mathrm{M}_{3}$ muscarinic receptors as targets for drug development in neurodegenerative disorders
}

\section{Mike Dragunow}

In their recent article, Wess et al. ${ }^{1}$ (Nature Rev. Drug Discov. 6, 721-733; 2007) elegantly reviewed the power of mutant-mice studies to provide insights into the functions of muscarinic receptors for drug development purposes. These studies have highlighted the role of muscarinic receptor subtypes as targets for drug development in important conditions including diabetes, obesity, pain, asthma, Alzheimer's disease and schizophrenia, and should help to stimulate work in these areas. Other roles for muscarinic receptor signalling that were not covered in the Wess et al. review, but that may also be relevant to drug development, include the control of apoptosis in neural cells.

Yan et al. ${ }^{2}$ demonstrated that activation of $\mathrm{M}_{3}$ muscarinic receptors on cultured cerebellar granule cells inhibited apoptosis, and similar results have been reported using human neuroblastoma cell lines ${ }^{3,4}$ and in $\mathrm{M}_{3}$ muscarinic receptor transfected cells ${ }^{4} . \mathrm{M}_{3}$ receptors are linked to several downstream pathways that may mediate this cell survival effect, including the anti-apoptotic gene BCL2 (REF. 5), cyclic AMP response element binding protein $(\mathrm{CREB})^{6}$, hypoxia-inducible factor 1 $(\mathrm{HIF} 1)^{7}$, nuclear factor- $\kappa \mathrm{B}(\mathrm{NF}-\kappa \mathrm{B})^{8}$, and soluble amyloid precursor protein- $\alpha^{8} . M_{3}$ muscarinic receptor signalling may also mediate the cardioprotective effects of choline ${ }^{9}$. The coupling of the $\mathrm{M}_{3}$ muscarinic receptor to the activation of CREB is especially relevant to cell survival given the important role of CREB in promoting survival of nerve cells ${ }^{10}$.

These neuroprotective actions of $\mathrm{M}_{3}$ muscarinic receptor activation may have implications for the treatment of nerve-cell death in neurodegenerative disorders such as Alzheimer's disease because $M_{3}$ receptors are widely expressed in the normal human brain and remain largely intact in Alzheimer's brain $^{11}$. Furthermore, activation of the $\mathrm{M}_{3}$ muscarinic receptor may aid in Alzheimer's disease by increasing the production of soluble amyloid precursor protein- $\alpha^{12}$.
Although there is strong in vitro support for a cytoprotective role for $\mathrm{M}_{3}$ receptor activation (as described above), the in vivo data in this area is sparse. Applying the power of the mutant-mouse technology, as described by Wess et al. ${ }^{1}$ to this area of investigation would help determine whether these in vitro results are relevant to the in vivo situation and might translate to therapies for neurodegenerative disorders such as Alzheimer's disease.

$$
\begin{array}{r}
\text { Mike Dragunow is at the Department } \\
\text { of Pharmacology, The University of Auckland, } \\
\text { Auckland, New Zealand. } \\
\text { e-mail: m.dragunow@auckland.ac.nz }
\end{array}
$$

1. Wess, J., Eglen, R. M. \& Gautam, D. Muscarinic acetylcholine receptors: mutant mice provide new insights for drug development. Nature Rev. Drug Discov. 6, 721-733 (2007).

2. Yan, G. M., Lin, S. Z., Irwin, R. P. \& Paul, S. M. Activation of muscarinic cholinergic receptors blocks apoptosis of cultured cerebellar granule neurons. Mol. Pharmacol. 47, 248-257 (1995).

3. De Sarno, P. et al. Muscarinic receptor activation protects cells from apoptotic effects of DNA damage, oxidative stress, and mitochondrial inhibition. J. Biol. Chem. 278, 11086-11093 (2003).

4. Budd, D. C., Spragg, E. J., Ridd, K. \& Tobin, A. B. Signalling of the $\mathrm{M}_{3}$-muscarinic receptor to the antiapoptotic pathway. Biochem. J. 381, 43-49 (2004).

5. Itano, Y., Ito, A., Uehara, T. \& Nomura, Y. Regulation of BCL-2 protein expression in human neuroblastoma SH-SY5Y cells: positive and negative effects of protein kinases C and A, respectively. J. Neurochem. 67, 131-137 (1996)

6. Greenwood, J. M. \& Dragunow, M. Muscarinic receptormediated phosphorylation of cyclic AMP response element binding protein in human neuroblastoma cells. J. Neurochem. 82, 389-397 (2002).

7. Hirota, K. et al. Induction of hypoxia-inducible factor 1 activity by muscarinic acetylcholine receptor signaling. J. Biol. Chem. 279, 41521-41528 (2004).

8. Choi, S. et al. Nuclear factor- $\mathrm{\kappa B}$ activated by capacitative $\mathrm{Ca}_{2}{ }^{+}$entry enhances muscarinic receptor-mediated soluble amyloid precursor protein (SAPP $\alpha$ ) release in SH-SY5Y cells. J. Biol. Chem. 281, 12722-12728 (2006).

9. Yang, B. et al. Choline produces cytoprotective effects against ischemic myocardial injuries: evidence for the role of cardiac $\mathrm{M}_{3}$ subtype muscarinic acetylcholine receptors. Cell. Physiol. Biochem. 16 163-174 (2005)

10. Walton, M. et al. CREB phosphorylation promotes nerve cell survival. J. Neurochem. 73, 1836-1842 (1999).

11. Rodriguez-Puertas, R., Pascual, J., Vilaro, T. \& Pazos, A. Autoradiographic distribution of $M_{1}, M_{2}, M_{3}$, and $M_{4}$ muscarinic receptor subtypes in Alzheimer's disease. Synapse 26, 341-350 (1997).

12. Slack, B. E., Ma, L. K. \& Seah, C. C. Constitutive shedding of the amyloid precursor protein ectodomain is up-regulated by tumour necrosis factor- $\alpha$ converting enzyme. Biochem. J. 357, 787-794 (2001). 